\title{
PEMANFAATAN BUBUK DAUN SIRIH (Piper betle L.) UNTUK MENINGKATKAN STATUS KESEHATAN IKAN NILA GIFT (Oreochromis niloticus)
}

\author{
Hamsah dan Wellem H. Muskita \\ Fakultas Perikanan dan IImu Kelautan, Universitas Haluoleo \\ Kampus Bumi Tridharma Andounohu, Kendari 93232 \\ E-mail: h4m_s4h@yahoo.co.id \\ E-mail:Wmuskita@yahoo.com
}

(Naskah diterima: 12 Mei 2009; Disetujui publikasi: 25 Januari 2010)

\begin{abstract}
ABSTRAK
Penelitian ini dilakukan untuk mengetahui efektivitas bubuk daun sirih yang dicampur dalam pakan (pelet) untuk meningkatkan status kesehatan ikan nila Gift dengan mengukur nilai hematokrit dan jumlah leukosit. Pengukuran nilai hematokrit dan jumlah leukosit darah ikan nila Gift dilakukan setelah ikan uji diberi pakan yang telah dicampur bubuk daun sirih $(0,2 \mathrm{~g} / 100 \mathrm{~g}$ pakan; $0,3 \mathrm{~g} / 100 \mathrm{~g}$ pakan; $0,4 \mathrm{~g} / 100 \mathrm{~g}$ pakan) selama 4 minggu masa pemeliharaan. Sedang ikan kontrol selama masa pemeliharaan diberi pakan pelet yang tidak dicampur bubuk daun sirih. Nilai hematokrit dan jumlah leukosit ikan nila Gift diukur setiap minggu dengan cara mengambil darah pada bagian vena caudal (ekor) ikan uji. Pengambilan darah dilakukan dengan menggunakan jarum suntik steril yang berukuran 26G, yang terlebih dahulu dibasahi Na-Sitrat 3,8\% sebagai antikoagulan. Selanjutnya, darah yang telah diambil ditampung dalam tabung eppendorf yang juga telah dibasahi Na-Sitrat, kemudian dipreparasi lalu diukur nilai hematokrit dan jumlah leukositnya. Hasil pengukuran menunjukkan bahwa nilai hematokrit ikan nila Gift yang diberi pakan yang dicampur bubuk daun sirih mengalami peningkatan berkisar dari $17 \%$ (minggu I) menjadi $28,66 \%$ (minggu IV), jumlah leukositnya meningkat dari $28,243 \mathrm{sel} / \mathrm{mm}^{3}$ (minggu I) menjadi $32,813 \mathrm{sel} / \mathrm{mm}^{3}$ (minggu IV). Dari hasil penelitian ini menunjukkan bahwa penambahan bubuk daun sirih dalam pakan mampu meningkatkan status kesehatan ikan nila Gift.
\end{abstract}

KATA KUNCI: daun sirih, hematokrit, leukosit, nila Gift

ABSTRACT: Utilisation of betel leaf powder (Piper betle L.) to improve health status of nila Gift (Oreochromis niloticus). By: Hamsah and Wellem H. Muskita

The research had been conducted to evaluate the efficacy of betel leaf powder mixed with fish feed (pellet) to improve health status of nila gift indicated by hematocrit value and number of leukocyte. The measurement of hematocrit value and number of leukocyte was done after the fish were fed with pellet mixed with betel leaf powder $(0.2$ $\mathrm{g} / 100 \mathrm{~g}$ pellet; $0.3 \mathrm{~g} / 100 \mathrm{~g}$ pellet; $0.4 \mathrm{~g} / 100 \mathrm{~g}$ pellet) for 4 weeks culture period while control fish during that period was fed with free-betel leaf powder pellet. Hematocrit value and leukocyte number were measured weekly by collecting blood sample from caudal vein of treated fish using syringe sized 26C containing Na Citrate $3.8 \%$ serving as anticoagulant. The blood samples were then placed in eppendorfs containing anticoagulant, prepared and then measured for its hematocrit value and number of leukocyte. The result showed that hematocrit value of nila tilapia Gift fed with betel leaf powder-pellet had increased from $17 \%$ (week 1) to $28.66 \%$ (week 4) while number of leukocyte had increased from $28.243 \mathrm{cel} / \mathrm{mm}^{3}$ (week 1) to $32.813 \mathrm{cel} / \mathrm{mm}^{3}$ (week 4). 
Research result demonstrated that supplementation of betel leaf powder on fish feed could increase the health status of nila Gift.

KEYWORDS: betel leaf, hematocrit, leukocyte, nila Gift

\section{PENDAHULUAN}

Salah satu masalah yang dihadapi dalam budidaya ikan nila Gift (Oreochromis niloticus) adalah adanya serangan penyakit. Beberapa jenis penyakit yang sering menyerang ikan nila Gift dan menyebabkan kerugian pada petani ikan antara lain penyakit MAS (Motile Aeromonad Septicaemia), Ichthyopthiriasis, Trichodiniasis, dan Saprolegniasis. Munculnya penyakit ikan tersebut antara lain disebabkan oleh buruknya kualitas lingkungan budidaya dan rendahnya daya tahan (kekebalan) tubuh ikan dalam menghadapi serangan penyakit (Angka, 1997).

Pengendalian penyakit harus dilakukan sedini mungkin, agar tidak terjadi kerugian ekonomi. Upaya pengendalian biasa dilakukan dengan pemakaian bahan kimia seperti antibiotik (oxytetracycline, oxolinic acid, erytromycin, streptomycin, dan kanamycin). Namun, penggunaan antibiotik yang terusmenerus justru dapat menimbulkan dampak negatif bagi lingkungan perairan, resistensi patogen, dan residu antibiotik yang berdampak pada kesehatan konsumen dan pemasaran (Alifuddin, 1999).

Immunostimulan merupakan salah satu alternatif pengganti antibiotik dan vaksin dalam perlindungan terhadap serangan penyakit (Robertsen et al., 1990). Selanjutnya dinyatakan bahwa immunostimulan merupakan senyawa biologis dan sintetis yang dapat meningkatkan pertahanan non-spesifik pada hewan. Sirih (Piper betle L.) merupakan tanaman obat yang berfungsi sebagai immunostimulan (Mangampa \& Atmomarsono, 1999; Sutama, 2002).

Sejauh ini belum banyak dikaji seberapa besar pengaruh pemberian bubuk daun sirih terhadap peningkatan daya tahan tubuh (status kesehatan) pada ikan. Atas dasar pertimbangan tersebut dipandang perlu dilakukan penelitian untuk mengetahui pengaruh penambahan bubuk daun sirih dalam pakan terhadap peningkatan daya tahan/ status kesehatan (persentase hematokrit dan jumlah leukosit) ikan nila Gift (O. niloticus).

\section{METODE PENELITIAN}

Penelitian ini dilaksanakan pada bulan Juni sampai Agustus 2008. Pembuatan bubuk daun sirih, pakan perlakuan, dan pemeliharaan hewan uji dilakukan di Laboratorium Jurusan Perikanan Fakultas Perikanan dan Ilmu Kelautan Universitas Haluoleo, Kendari. Sementara preparasi dan pengukuran hematokrit dan jumlah leukosit darah ikan dilakukan di Laboratorium Kesehatan Rumah Sakit Umum Kendari.

Pembuatan bubuk daun sirih dilakukan dengan cara mencuci bersih daun sirih lalu dikeringkan dalam oven dengan suhu $60^{\circ} \mathrm{C}$ selama 20 jam. Setelah itu daun di-blender, lalu diayak dengan saringan berdiameter $1 \mathrm{~mm}$ sehingga menjadi bubuk. Kemudian bubuk daun sirih pada level dosis tertentu dicampurkan secara merata ke dalam setiap $100 \mathrm{~g}$ pakan pelet yang berkadar protein $25 \%$ yang kemudian menjadi perlakuan dalam percobaan ini.

Hewan uji yang digunakan adalah ikan nila Gift yang berukuran $50 \pm 1 \mathrm{~g}$ diperoleh dari BBI Abelisawah Kota Kendari. Sebelum perlakuan, terlebih dahulu dilakukan proses adaptasi hewan uji dengan kondisi lingkungan penelitian selama satu minggu. Sebelum pemberian pakan uji, terlebih dahulu dilakukan pengambilan darah ikan untuk menentukan persentase hematokrit dan jumlah leukosit awal ikan nila Gift.

Percobaan pemberian pakan yang mengandung bubuk daun sirih dirancang dengan menggunakan Rancangan Acak Lengkap (RAL) dengan 3 perlakuan ditambah 1 perlakuan kontrol dan masing-masing 3 ulangan. Ketiga perlakuan tersebut mengacu pada dosis yang digunakan Direkbusarakom et al. (1997) dan Yulita (2002) yaitu pakan yang mengandung bubuk daun sirih $0,2 \mathrm{~g} / 100 \mathrm{~g}$ pakan; $0,3 \mathrm{~g} /$ $100 \mathrm{~g}$ pakan; dan 0,4 g/100 g pakan. Sementara perlakuan kontrol, ikan uji diberi pakan pelet yang tidak mengandung bubuk daun sirih. Padat tebar ikan nila Gift yang digunakan sebanyak 10 ekor per akuarium $(40 \mathrm{~cm} \times 40$ $\mathrm{cm} \times 80 \mathrm{~cm}$ ) dengan volume air 50 liter. 
Pakan yang mengandung bubuk daun sirih diberikan selama 1 bulan (lama penelitian), sebanyak $12 \%$ dari bobot badan per hari dengan frekuensi pemberian pakan 3 kali (pagi, siang, dan sore hari). Untuk menjaga kualitas air tetap baik dilakukan penyiponan dan pergantian air sebanyak $10 \%$ per hari.

Respons kekebalan (status kesehatan) ikan nila Gift ditentukan dengan menghitung persentase hematokrit dan jumlah leukosit darah ikan nila Gift tersebut. Pengukuran persentase hematokrit dan jumlah leukosit darah dilakukan setiap minggu (selama 4 minggu) dengan cara mengambil darah pada bagian vena caudal (ekor) ikan uji dengan jumlah sampel sebanyak 2 ekor per perlakuan per minggu. Pengambilan darah dilakukan dengan menggunakan jarum suntik steril yang berukuran 26G, yang terlebih dahulu dibasahi Na-Sitrat $3,8 \%$ sebagai antikoagulan. Selanjutnya, darah yang telah diambil ditampung dalam tabung eppendorfyang juga telah dibasahi Na-Sitrat.

Proses pengukuran hematokrit menurut Alifuddin (1996) adalah sebagai berikut:

1. Pipet kapiler diisi dengan darah yang langsung mengalir atau dengan darah yang telah diberi antikoagulan sebanyak 3/4 bagian.

2. Salah satu dari ujung pipet disumbat dengan menggunakan dempul (kristoseal) agar darah tidak keluar.

3. Pipet kapiler dimasukkan ke dalam alat mikrosentrifus, lalu disentrifus dengan kecepatan 2.000 rpm selama 5 menit.

4. Pengukuran kadar hematokrit dilakukan dengan cara membandingkan volume sel darah terhadap volume seluruh darah dengan menggunakan skala hematokrit yang nilainya dinyatakan dalam persentase hematokrit $(\% \mathrm{Ht})$.

$$
\begin{gathered}
\text { Hematokrit }=\frac{\begin{array}{l}
\text { Panjang tabung yang } \\
\text { berisi sel darah merah/ } \\
\text { eritrosit }
\end{array}}{\begin{array}{l}
\text { Panjang tabung yang } \\
\text { berisi keseluruhan darah }
\end{array}} \times 100 \%
\end{gathered}
$$

Proses pengukuran leukosit menurut Alifuddin (1996) adalah sebagai berikut:

1. Sebelum dilakukan perhitungan, terlebih dahulu dilakukan pengenceran sel darah dengan menggunakan larutan Turk agar sel darah dapat pecah sehingga sel darah putih (leukosit) dapat diamati.

2. Mengambil larutan pengencer sebanyak $500 \mu \mathrm{L}$ dengan menggunakan pipet volumetrik lalu dimasukkan ke dalam tabung.

3. Menambahkan $20 \mu \mathrm{L}$ darah ke dalam tabung, kemudian tabung tersebut digoyangkan agar larutannya homogen.

4. Setelah pengenceran, kemudian sel darah dimasukkan ke dalam haemocytometer dan ditutup dengan menggunakan kaca penutup, dibiarkan beberapa menit hingga mengendap.

5. Diamati di bawah mikroskop, lalu dihitung jumlah sel leukositnya sebagai berikut:

Total leukosit $=$ Jumlah sel leukosit $\mathrm{x}$ faktor pengenceran

\section{Analisis Data}

Data hasil pengukuran persentase hematokrit dan jumlah leukosit ikan nila Gift pada masing-masing perlakuan dianalisa dengan menggunakan analisis ragam (ANOVA), jika berbeda nyata maka dilanjutkan dengan Uji Beda Nyata Terkecil (BNT) pada taraf kepercayaan 95\% (Gaspersz, 1995).

\section{HASIL DAN BAHASAN}

\section{Nilai Hematokrit}

Rata-rata persentase hematokrit ikan nila Gift yang diberi pakan yang dicampur bubuk daun sirih selama 4 minggu pemeliharaan dapat dilihat pada Gambar 1.

Pada Gambar 1 terlihat persentase hematokrit ikan nila Gift berbeda pada setiap dosis pemberian bubuk daun sirih dalam pakan perlakuan. Pada pemberian pakan yang dicampur bubuk daun sirih, persentase hematokrit tertinggi diperoleh pada perlakuan C (0,4 g/100 g pakan) sebesar $28,66 \%$; disusul perlakuan $B(0,3 \mathrm{~g} / 100 \mathrm{~g}$ pakan $)$ sebesar $26,33 \%$; perlakuan A $(0,2 \mathrm{~g} / 100 \mathrm{~g}$ pakan) sebesar 24\%, dan terendah diperoleh pada perlakuan $\mathrm{D} /$ kontrol $(0 \mathrm{~g} / 100 \mathrm{~g}$ pakan) sebesar $17,33 \%$.

Perbedaan persentase hematokrit ikan nila Gift pada pemberian pakan yang dicampur bubuk daun sirih sangat terkait dengan banyaknya bubuk daun sirih yang dicampurkan dalam pakan perlakuan dan respons ikan nila Gift terhadap setiap pakan 


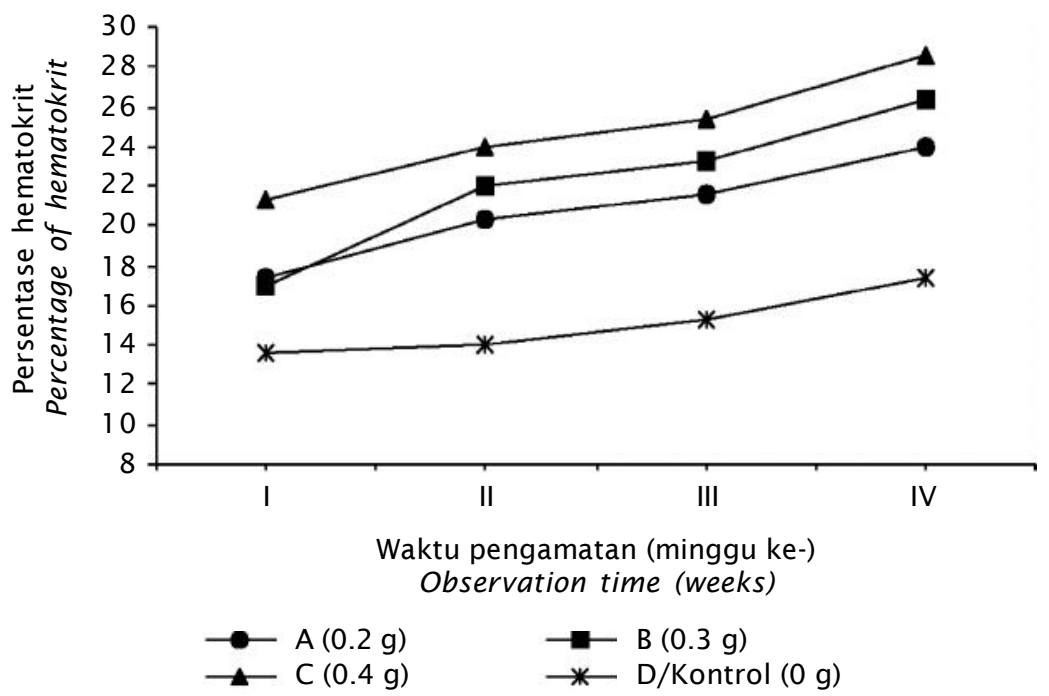

Gambar 1. Rata-rata persentase hematokrit ikan nila Gift yang diberi pakan dengan dicampur bubuk daun sirih

Figure 1. The average percentage of hematocrit of nila tilapia Gift fed with betel leaf powder-pellet

yang diberikan. Makin tinggi dosis bubuk daun sirih yang dicampurkan dalam pakan perlakuan, cenderung meningkatkan persentase hematokrit ikan nila Gift. Sementara respons ikan nila Gift terhadap pakan perlakuan cukup baik. Hal ini terlihat dari aktivitas makan yang cukup baik setiap kali pemberian pakan dan jumlah sisa pakan pada dasar akuarium yang relatif sedikit.

Pengaruh bubuk daun sirih yang dicampurkan dalam pakan perlakuan terhadap persentase hematokrit ikan nila Gift juga bergantung pada hari pengamatan. Persentase hematokrit ikan nila Gift yang diberi pakan perlakuan cenderung meningkat dengan bertambahnya hari pengamatan (Gambar 1). Pada pemberian pakan yang dicampur bubuk daun sirih sebanyak 0,2 g/100 g pakan (perlakuan A), persentase hematokrit ikan nila Gift meningkat dari 17,33\% (minggu I) menjadi $24 \%$ (minggu IV). Pemberian sebanyak $0,3 \mathrm{~g} /$ $100 \mathrm{~g}$ pakan (perlakuan B), persentase hematokrit meningkat dari 17\% (minggu I) menjadi 26\% (minggu IV); pemberian sebanyak $0,4 \mathrm{~g} / 100 \mathrm{~g}$ pakan (perlakuan $\mathrm{C}$ ), persentase hematokrit meningkat dari $21,33 \%$ (minggu I) menjadi 28,66\% (minggu IV).

Hasil analisis ragam, menunjukkan bahwa pemberian pakan yang dicampur bubuk daun sirih memberikan pengaruh yang nyata terhadap persentase hematokrit ikan nila Gift $\left(F_{\text {hit }}>F_{\text {tab }} 0,05\right)$. Hasil uji BNT, menunjukkan bahwa persentase hematokrit setiap perlakuan penambahan bubuk daun sirih dalam pakan tidak berbeda nyata, namun ketiganya berbeda nyata dengan kontrol. Ini menunjukkan bahwa pemberian pakan yang dicampur bubuk daun sirih dapat memperbaiki dan meningkatkan status kesehatan ikan nila Gift sehingga persentase hematokritnya meningkat (tinggi) dibandingkan dengan persentase hematokrit ikan nila Gift yang diberi pakan yang tidak dicampur dengan bubuk daun sirih (kontrol). Hal ini dimungkinkan karena bubuk daun sirih mengandung bahan yang berfungsi sebagai antibakteri dan immunostimulan yang dapat meningkatkan sistem pertahanan non spesifik ikan (Sutama, 2002). Menurut Snieszko et al. (1974) dalam Saptiani (1996), nilai hematokrit berpengaruh terhadap tingkat kesehatan ikan terutama untuk mendeteksi terjadinya anemia, defisiensi vitamin, dan terjadinya infeksi pada ikan. Selanjutnya dinyatakan bahwa nilai hematokrit pada ikan berkisar antara 5\%-60\%. Menurut Randall (1970), nilai hematokrit yang lebih kecil dari 22\% menunjukkan bahwa ikan mengalami anemia dan kemungkinan terinfeksi penyakit. Nilai atau kadar hematokrit 
berhubungan dengan jumlah sel darah merah dan kadar hematokrit tersebut selalu berubahubah tergantung pada faktor nutrisi dan umur. Ferguson (1988) menyatakan bahwa nilai hematokrit variasinya tinggi karena sangat dipengaruhi oleh umur, jenis kelamin, waktu pemeriksaan, temperatur air, metode sampling, tipe, dan lama anestesi.

\section{Jumlah Leukosit}

Rata-rata jumlah leukosit ikan nila Gift yang diberi pakan dengan dicampur bubuk daun sirih selama 4 minggu pemeliharaan dapat dilihat pada Gambar 2 .

Pada Gambar 2 terlihat rata-rata jumlah leukosit ikan nila Gift berbeda pada setiap dosis pemberian bubuk daun sirih dalam pakan perlakuan. Rata-rata jumlah leukosit tertinggi diperoleh pada perlakuan $\mathrm{C}(0,4 \mathrm{~g} / 100 \mathrm{~g}$ pakan $)$ sebanyak $32,813 \mathrm{sel} / \mathrm{mm}^{3}$, disusul perlakuan B $(0,3 \mathrm{~g} / 100 \mathrm{~g}$ pakan $)$ sebanyak $31,477 \mathrm{sel} /$ $\mathrm{mm}^{3}$, perlakuan $\mathrm{A}(0,2 \mathrm{~g} / 100 \mathrm{~g}$ pakan) sebanyak $30,620 \mathrm{sel} / \mathrm{mm}^{3}$, dan terendah diperoleh pada perlakuan $\mathrm{D} / \mathrm{kontrol}(0 \mathrm{~g} / 100 \mathrm{~g}$ pakan) sebanyak $27.433 \mathrm{sel} / \mathrm{mm}^{3}$.

Makin tinggi dosis bubuk daun sirih yang dicampurkan dalam pakan perlakuan, cenderung meningkatkan jumlah leukosit ikan nila Gift. Pengaruh bubuk daun sirih yang dicampurkan dalam pakan perlakuan terhadap jumlah leukosit ikan nila Gift juga bergantung pada hari pengamatan. Jumlah leukosit ikan nila Gift yang diberi pakan perlakuan cenderung meningkat dengan bertambahnya hari pengamatan (Gambar 2).

Pada pemberian pakan yang dicampur bubuk daun sirih, rata-rata jumlah leukosit perlakuan A meningkat dari $28,277 \mathrm{sel} / \mathrm{mm}^{3}$ (minggu I) menjadi $30,620 \mathrm{sel} / \mathrm{mm}^{3}$ (minggu IV) atau sebesar $8,28 \%$; rata-rata jumlah leukosit perlakuan B meningkat dari $28,243 \mathrm{sel} / \mathrm{mm}^{3}$ (minggu I) menjadi $31,477 \mathrm{sel} / \mathrm{mm}^{3}$ (minggu IV) atau sebesar $11,45 \%$; rata-rata jumlah leukosit perlakuan C meningkat dari $29,767 \mathrm{sel} / \mathrm{mm}^{3}$ (minggu I) menjadi $32,813 \mathrm{sel} / \mathrm{mm}^{3}$ (minggu IV) atau sebesar 10,23\%; sementara rata-rata jumlah leukosit perlakuan D/kontrol meningkat dari $25.820 \mathrm{sel} / \mathrm{mm}^{3}$ (minggu I) menjadi 27,433 $\mathrm{sel} / \mathrm{mm}^{3}$ (minggu IV) atau sebesar $6,25 \%$.

Hasil analisis ragam, menunjukkan bahwa pemberian pakan yang dicampur bubuk daun sirih memberikan pengaruh yang nyata terhadap rata-rata jumlah leukosit ikan nila Gift $\left(\mathrm{F}_{\text {hit }}>\mathrm{F}_{\text {tab }} 0,05\right)$. Ini menunjukkan bahwa pemberian pakan yang mengandung bubuk daun sirih dapat memperbaiki dan meningkatkan status kesehatan ikan nila Gift sehingga jumlah leukositnya meningkat (tinggi). Hal ini

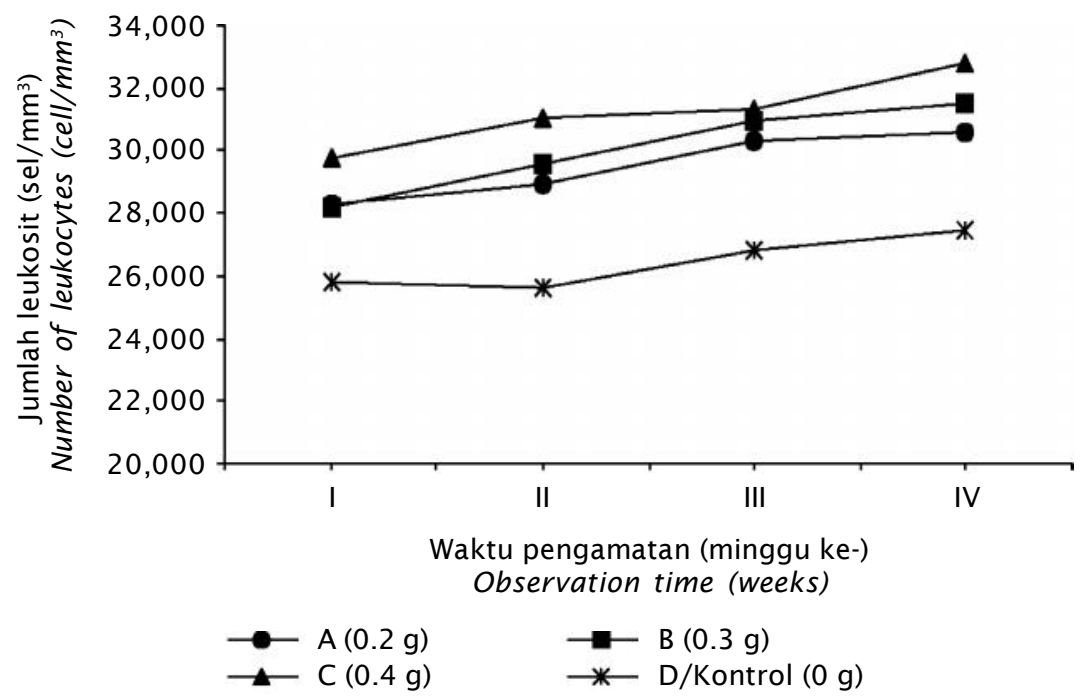

Gambar 2. Rata-rata jumlah leukosit ikan nila Gift yang diberi pakan dengan dicampur bubuk daun sirih

Figure 2. The average number of leukocytes of nila tilapia Gift fed with betel leaf powder-pellet 
dimungkinkan karena bubuk daun sirih mengandung bahan yang berfungsi sebagai immunostimulan yang dapat meningkatkan sistem pertahanan non spesifik ikan nila Gift. Kandungan kimia utama daun sirih adalah minyak atsiri, vitamin, asam organik, asam amino, gula, tanin, lemak, pati, dan karbohidrat yang berfungsi sebagai antibakteri, antiseptik, dan immunostimulan (Darwis, 1991; Sutama, 2002). Anderson (1974) menyatakan bahwa leukosit atau sel darah putih adalah sel yang bertanggung jawab dalam sistem pertahanan tubuh dan kemampuannya dapat ditingkatkan dengan menggunakan immunostimulan, vitamin, dan hormon.

Hasil uji BNT, menunjukkan bahwa setiap perlakuan penambahan bubuk daun sirih dalam pakan tidak berbeda nyata, namun ketiganya berbeda nyata dengan kontrol. Ini menunjukkan bahwa peningkatan nilai hematokrit dan jumlah leukosit ikan nila Gift yang diberi pakan dengan dicampur bubuk daun sirih selama 4 minggu masa pemeliharaan relatif sama. Hal ini dimungkinkan kondisi kesehatan ikan nila Gift selama penelitian relatif baik pada semua perlakuan sehingga nilai hematokrit dan jumlah leukositnya juga relatif tidak berbeda. Anderson (1992), menyatakan bahwa leukosit akan meningkat secara pesat apabila terjadi suatu infeksi. Lebih lanjut dijelaskan bahwa leukosit merupakan salah satu komponen darah yang berfungsi sebagai pertahanan non spesifik yang akan melokalisasi dan mengeliminir patogen melalui pagositosis. Sel darah putih (leukosit) ikan tidak berwarna dan jumlahnya sekitar 20.000-150.000 sel/ $\mathrm{mm}^{3}$ darah (Rastogi, 1977). Leukosit pada ikan terdiri atas neutrofil, monosit, limfosit, dan trombosit.

\section{KESIMPULAN DAN SARAN}

Berdasarkan hasil penelitian yang telah dilakukan, dapat disimpulkan bahwa:

1. Penambahan bubuk daun sirih dalam pakan dapat meningkatkan status kesehatan ikan nila Gift yang dibuktikan oleh peningkatan nilai hematokrit dan jumlah leukosit ikan nila Gift yang diberi perlakuan.

2. Penambahan bubuk daun sirih dalam pakan mampu meningkatkan rata-rata nilai hematokrit dan jumlah leukosit ikan nila Gift masing-masing berkisar dari 17\% (minggu I) menjadi 28,66\% (minggu IV), dan dari 28.243 $\mathrm{sel} / \mathrm{mm}^{3}$ (minggu I) menjadi $32.813 \mathrm{sel} / \mathrm{mm}^{3}$ (minggu IV).
Untuk meningkatkan status kesehatan ikan nila Gift dapat diaplikasikan pakan yang dicampur dengan bubuk daun sirih sebanyak $0,3 \mathrm{~g} / 100 \mathrm{~g}$ pakan.

\section{DAFTAR ACUAN}

Alifuddin, M. 1996. Tinjauan pemeriksaan hematologik ikan. Laboratorium Kesehatan Ikan. Jurusan Budidaya Perairan, Fakultas Perikanan dan Ilmu Kelautan, Institut Pertanian Bogor. Bogor, $10 \mathrm{hlm}$.

Alifuddin, M. 1999. Peran Imunostimulan (Lipopolisakarida, Saccharomyces serevisiae, dan Levamisol) pada Gambaran Respon Imunitas Ikan Jambal Siam (Pangasius hypohthalmus Fowler). Tesis S-2. Program Studi Ilmu Perairan Pascasarjana IPB. Bogor, $78 \mathrm{hlm}$.

Anderson, D.P. 1974. Fish Imunologi, TFH Publication Ltd. Hongkong, 239 pp.

Anderson, D.P. 1992. Immunostimulants, Adjuvants, and Vaccine Carriers in Fish: Applications to Aquaculture. Ann. Rev. Fish Dis., 2: 281-307.

Angka, S.L. 1997. Antibiotic Sensitivity and Pathogenicity of Aeromonas and Vibrio Isolates in Indonesia. In: Flegel, T.W. and Mac Rae, I.H. (Eds.). Diseases in Asian Aquaculture III. Fish Health Section, Asian Fisheries Society, Manila, p. 339-347.

Darwis. 1991. Potensi sirih (Piper betle Linn.) sebagai tanaman obat. Di dalam Warta Tumbuhan Obat Indonesia, 1(1): 9-11.

Direkbusarakom, S., Herusalee, A., Yoshimuzu, M., Ezura, Y., \& Kimura, T. 1997. Efficacy of Guava (Psidium guajava) Extract Againts Some Fish and Shrimp Pathogenic Agents. In: Flegel T.W. and Mac Rae, I.H. (Eds.). Diseases in Asian Aquaculture III. Fish Health Section, Asian Fisheries Society, Manila, $363 \mathrm{pp}$.

Ferguson, H.W. 1988. Normal Structure and Functions. Fish Disease Refresher Course for Veterinarians Proc., 106: 35-47.

Gaspersz, V. 1995. Teknik Analisis dalam Penelitian Percobaan, Jilid 2. Penerbit Tarsito, Bandung, hlm. 718.

Mangampa, M. \& Atmomarsono. 1999. Pengaruh Penggunaan Immunostimulan pada Ransum Benur Udang Windu yang Ditokolkan. Balai Penelitian Perikanan Pantai, Maros, hlm. 2433.

Randall, D.J. 1970. The Circulatory System. In Fish Physiology ed: W.S. Hoar, D.J. Randall. 
Vol 4 London Academic Press, p. 133-172.

Rastogi, S.C. 1977. Essential of Animal Physiology. Willley Easterm Limited, New Delhi, Bangalore, Bombay, Calcuta, p. 204-223.

Robertsen, B., Roerstad, G., Engstad, R, \& Raa, J. 1990. Enhancement of Nonspesifik Diseases Resistence in Atlantic Salmon (Salmo salar L.) by a Glucan from Saccharomyces serevisiae. Cell - Walls of Fish Diseases, 13: 391.

Saptiani, G. 1996. Gambaran sistem kekebalan non spesifik pada ikan gurame (Osphronemus gouramy) akibat pemberian immunostimulan. Program Pasca Sarjana IPB. Bogor, $60 \mathrm{hlm}$.
Sutama, I.K.J. 2002. Efektivitas ekstrak daun jambu biji, sambiloto dan daun sirih terhadap infeksi bakteri Aeromonos hydrophila L3 1 pada ikan Lele Dumbo (Clarias sp.). Skripsi. Fakultas Perikanan dan Ilmu Kelautan IPB. Bogor, $76 \mathrm{hlm}$.

Yulita, I. 2002. Efektivitas bubuk daun jambu biji, daun sirih, dan daun sambiloto untuk pencegahan dan pengobatan pada ikan lele dumbo (Clarias sp.) yang diinfeksi dengan bakteri Aeromonas hydrophila. Skripsi. Fakultas Perikanan dan IImu Kelautan Institut Pertanian Bogor. Bogor, $96 \mathrm{hlm}$. 